\title{
Verde urbano na conservação da biodiversidade em João Pessoa, Paraíba
}

\section{Urban green in conservation of biodiversity in João Pessoa, Paraiba, Brazil}

\author{
Yuri Rommel Vieira Araújo ${ }^{1}$; Zayne Christina Gonçalves Moreira ${ }^{2}$ \\ ${ }^{1}$ Mestre em Energias Renováveis e graduação em Engenharia Florestal, Universidade Federal da Paraíba, João Pessoa, Paraíba (83) 987742006, \\ yuriaraujo@ florestal.eng.br; ${ }^{2}$ Graduanda em Geografia, graduada em Administração e especialização em Gestão Ambiental, Universidade Federal da Paraíba, João \\ Pessoa, Paraíba, zaynemoreira@gmail.com.br
}

\section{A R T I G O}

Recebido: 03/04/2019

Aprovado: 06/12/2019

\section{Palavras-chave:}

Remanescentes florestais

Arborização urbana

Espécies ameaçadas

Forest remnants

Arborization urban

Endangered species

\section{Key words:}

\section{R E S U M O}

$\mathrm{O}$ crescimento urbano tem alterado cada vez mais às características naturais dos ecossistemas em áreas povoadas, resultando na redução de áreas naturais e de biodiversidade. Para minimizar os impactos negativos da expansão urbana são criadas as áreas verdes e áreas protegidas. Neste contexto, este estudo objetivou analisar a importância do verde urbano existente na área urbana do município de João Pessoa, Paraíba, para a conservação da biodiversidade em um aglomerado populacional. O método consistiu na pesquisa exploratória e explicativa, com levantamento bibliográfico do acevo público e trabalho de campo em áreas verdes, parques, praças, remanescentes florestais, áreas de preservação e Unidades de Conservação. Foram identificadas 85 espécies arbóreas e palmeiras de 34 famílias diferentes, onde sete foram enquadradas em perigo de extinção. Também foram identificadas 36 espécies de aves, nove de répteis e oito mamíferos. Constatou-se uma interação entre grupos específicos da fauna com espécies da flora. O verde urbano de João Pessoa contribui para a conservação da flora nativa e espécies ameaçadas de extinção; existem grupos de aves, mamíferos e répteis utilizando o verde urbano para alimentação, abrigo ou alimentação, e; o município apresenta uma diversidade de espécies relevantes, mesmo assim, há a necessidade de criar áreas protegidas.

\section{A B S T R A C T}

Urban growth has increasingly altered the natural characteristics of ecosystems in populated areas, resulting in the reduction of natural areas and biodiversity. To minimize the negative impacts of urban sprawl, green areas and protected areas are created. In this context, this study aimed to analyze the importance of urban green in the urban area of João Pessoa, Paraíba, for the conservation of biodiversity in a population cluster. The method consisted of exploratory and explanatory research, with bibliographic survey of public access and field work in green areas, parks, squares, forest remnants, preservation areas and Conservation Units. We identified 85 tree and palm species from 34 different families, seven of which were endangered. Thirty six bird species, nine reptile species and eight mammal species were also identified. An interaction between specific groups of fauna and species of flora was found. The urban green of João Pessoa-PB contributes to the conservation of native flora and endangered species; there are groups of birds, mammals and reptiles using urban green for food, shelter or feeding, and; the municipality has a diversity of relevant species, yet there is a need to create protected areas.

\section{INTRODUÇÃO}

As rápidas modificações da paisagem e as mudanças sem planejamento nas últimas décadas, induzidas principalmente pela expansão urbana, provocaram uma série de alterações no uso do solo, destruição, fragmentação dos espaços naturais e ao isolamento de habitats naturais, causando prejuízo para a biodiversidade (MACIEL; BARBOSA, 2015). Neste contexto, os ambientes naturais existentes nos perímetros urbanas, tem recebido atenção para a conservação da fauna, além de exercer funções estéticas e de lazer, onde, atualmente, encontra-se em

\footnotetext{
Revista Verde

ISSN 1981-8203

Pombal, Paraíba, Brasil
}

v. 15, n.1, jan.-mar, p.73-82, 2020

doi: 10.18378/rvads.v15i1.6494 
locais de proteção ambiental e/ou classificadas como áreas verdes (VILANOVA; MAITELLI, 2009).

Estas áreas são consideradas como áreas livres, com predominância de vegetação arbórea, acessível ao uso da população, proporcionando inúmeros benefícios, a exemplo da qualidade e equilíbrio ambiental, além da saúde e bem-estar da população, constituindo assim, um recurso importante para o planejamento e desenvolvimento de um ambiente urbano mais saudável (LONDE; MENDES, 2014).

Nas áreas verdes das quadras no perímetro urbano do município de Palmas-TO, tratando-se de locais não edificáveis, observou-se que as mesmas apresentam importância no ponto de vista socioeconômico e ambiental, devido à elevada proporção de espécies arbóreas com múltiplos usos, garantindo o fornecimento de alimentos para humanos, animais e aplicação medicinal (PINHEIRO et al, 2018).

Entre as áreas verdes existentes no perímetro urbano, além das praças e parques, podemos citar as de preservação permanentes e remanescentes florestais. Os remanescentes florestais ou florestas urbanas, desenvolvem diversos serviços ecossistêmicos em área densamente povoada, a exemplo do vale de Aburrá (Colômbia) que captura aproximadamente 228 toneladas de poluentes atmosféricos por ano (ARROYAVEMAYA et al., 2018). Na mata ciliar do rio Torres, cidade de San José-Costa Rica, Quesada-Acuña et al. (2018), constataram a interação existente entre a fauna e as áreas verdes, servindo de locais de fornecimento de alimento e abrigo, e favorecendo a regeneração da vegetação nativa. Em outro exemplo, no município de Iquito - Perú, a riqueza de espécies de avefauna no ambiente urbano se mantém, devido às condições ambientais existentes na cidade, onde os pomares de árvores frutíferas existentes na grande maioria das casas atraem os pássaros, servindo de poleiros, lugar de reprodução e nidificação (VÁSQUEZ et al., 2016).

Com relação à interação entre o verde urbano e a fauna alguns estudos tem abordado esta temática nos últimos anos. No município de Três Rios-RJ, em uma área de parque e praças, Estrada et al. (2014), estudaram o grupo de Mirmecofauna, tratando-se das espécies de formigas. No fragmento urbano do município de Campo Grande -MS, Bogiani et al. (2012) estudaram o grupo das Lepidopteras, sendo identificadas 62 espécies de borboletas. Em área urbana no oeste da Bahia, Santos e Calado (2014) estudaram os mosquitos (Diptera: Culicidae) com o objetivo de verificar a presença de espécies de interesse em saúde pública. Em fragmentos florestais urbanos da bacia hidrográfica do Rio Cachoeira, Joinville-SC, Dornelles et al. (2017) registraram 32 espécies de mamíferos, incluindo gambás, tamanduás, morcegos, graxaim e gato-do-mato. Na Unidade de Conservação "Parque Estadual Dois Irmãos", localizado no Recife-PE, inserido totalmente em área urbana, Melo et al. (2018) registraram 34 espécies de anfíbios pertencentes a 10 famílias e 27 espécies de répteis, de 17 famílias.

Devido as constantes modificações das áreas naturais ainda existentes em áreas urbanas, a realização de uma análise sobre a importância destas áreas, para a conservação e permanência da diversidade de espécies nos conglomerados urbanos é indispensável. Em que, neste contexto, não foi encontrado estudo realizado no perímetro urbano do município de João Pessoa-PB. Desta forma, o presente estudo propôs analisar a importância do verde urbano existente no perímetro urbana do município de João Pessoa-PB, para a conservação da biodiversidade em um aglomerado populacional.

\section{MATERIAL E MÉTODOS}

A cidade de João Pessoa apresenta uma densidade demográfica de $3.421,30 \mathrm{hab} / \mathrm{km}^{2}$, com uma área territorial de $211,474 \mathrm{~km}^{2}$ e população total de 723.515 habitantes, localizase no extremo leste da Paraíba. Cerca de $99,6 \%$ da população reside na área urbana (IBGE, 2019).

O município de João Pessoa faz parte da mesorregião da zona da mata paraibana, entre as coordenadas $7^{\circ} 14^{\prime} 29^{\prime \prime}$ de Latitude Sul / 34 $58^{\prime} 36^{\prime \prime}$ de Longitude Oeste e $7^{\circ} 03^{\prime} 18^{\prime \prime}$ de Latitude Sul / 3447’36" de Longitude Oeste. Limita-se, ao Sul, com o município do Conde, ao Oeste com os municípios de Bayeux e Santa Rita, ao Norte com o município de Cabedelo e ao Leste com o Oceano Atlântico (Figura 1). Inserido sob o domínio da Bacia Geológico Pernambuco-Paraíba que se estende pelo litoral do estado de Pernambuco ao Rio Grande do Norte. Com solo formando mosaicos, com várias associações de solos, associados com Argissolos, Neossolos, Espodossolos, Organossolos, Gleissolos e Alissolos (JOÃO PESSOA, 2012)

Figura 1. Mapa de localização da área de estudo na cidade de João Pessoa, Paraíba, Brasil.
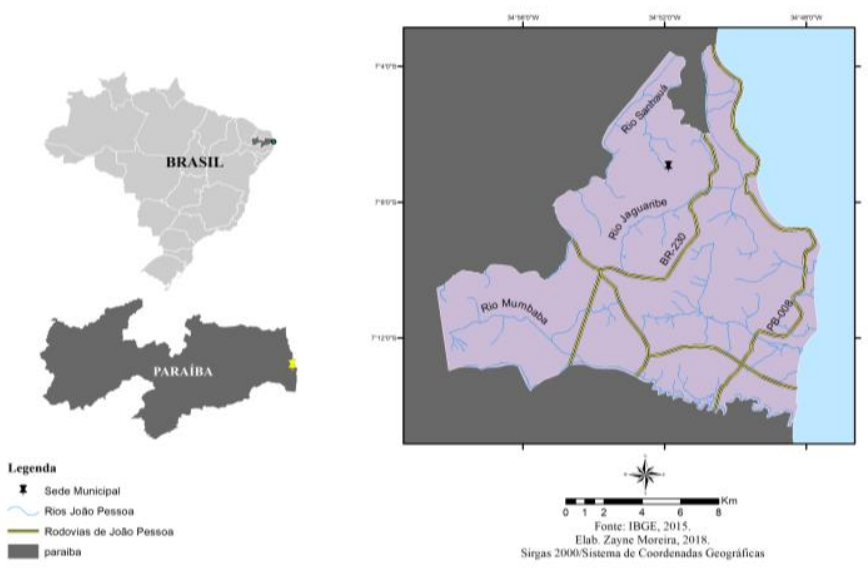

As temperaturas médias anuais do município oscilam em torno de $24^{\circ} \mathrm{C}$ do período considerado mais frios, julho e agosto, e de $28^{\circ} \mathrm{C}$ no período considerado mais quente, fevereiro. A precipitação anual médio dos últimos 30 anos foi de $1.700 \mathrm{~mm}$, com máximas entre abril e junho que podem ultrapassar os 300 $\mathrm{mm}$. De acordo com as classificações climáticas de Köppen o município encontra-se dentro do domínio tropical quente-úmido (MORAIS, 2009).

O município insere-se no bioma Mata Atlântica com formação florestal conhecida por Mata de Tabuleiro, composta por Floresta Estacional Semidecídual, Formação Litorânea, Campos de Várzea, Manguezais e Vegetação de Restinga (JOÃO PESSOA, 2012; MORAIS, 2009). Entre duas bacias hidrográficas, ao norte a Bacia do Rio Paraíba e ao sul a Bacia do Rio Gramame, entremeada pelas bacias hidrográficas dos rios Cabelo, Jaguaribe, Aratú, Jacarapé, Cuiá e Camurupim (MORAIS, 2009). 
O método utilizado consistiu na pesquisa exploratória e explicativa (SEVERINO, 2007), com levantamento bibliográfico e trabalho de campo com foco na observação e identificação das interações entre a biota existentes nas áreas naturais. Este tipo de pesquisa busca levantar informações sobre o objeto estudado, além de registrar, buscar identificar suas causas, seja através da aplicação do método experimental ou interpretação possibilitada pelo método qualitativo.

O trabalho teve inicio com a revisão bibliográfica, com o levantamento dos documentos do acervo público municipal sobre a condição das áreas naturais, áreas verdes e Unidades de Conservação, e florestas urbanas, no perímetro urbano de João Pessoa-PB. Em seguida houve o levantamento e coleta de dados, com a análise dos estudos, diagnósticos, pareceres e laudos técnicos elaborados pela Secretaria Municipal de Meio Ambiente de João Pessoa (Semam) das áreas verdes municipais do período entre 2013 e 2018.

Após estas duas etapas, foram realizadas observações in loco da interação (quanto à utilização da área para alimentação, abrigo ou reprodução) existente entre a fauna (vertebrado), flora e as áreas naturais, com a identificação das espécies faunísticas e arbóreas observadas nos remanescentes florestais do Parque Natural Municipal do Cuiá, Parque Cabo Branco, Parque Solón de Lucena, Parque Ecológico Augusto dos Anjos, Parque Lauro Pires Xavier, Parque Zoobotânico Arruda Câmara, áreas de preservação dos Rios Cuiá, Jaguaribe, Gramame e Riacho do Padre, e da cobertura arbórea das praças e canteiros centrais, mediante caminhadas no período entre 2015 e 2018.

Ao todo, foram realizadas 38 visitas in loco, sendo 3 no Parque Natural Municipal do Cuiá (294688.64 mE e 9204746.00 mS), 2 no Parque Cabo Branco (301598.83 mE e 9209256.77 mS), 3 no Parque Solón de Lucena (292526.22 mE e $9212629.62 \mathrm{mS}), 1$ no Parque Ecológico Augusto dos Anjos (295024.57 mE e 9202667 mS), 1 no Parque Lauro Pires Xavier (293813.74 mE e 9213015.27 mS), 1 no Parque Ecológico Jaguaribe (297847.77 mE e $9212359.58 \mathrm{mS}$ ), 2 no Parque Zoobotânico Arruda Câmara (292772.00 mE e 9213191.71 $\mathrm{mE}), 4$ na área de preservação do Rio Cuiá $(296920,86 \mathrm{mE}$ e $9204423.82 \mathrm{mS}), 3$ no Rio Jaguaribe (291662.29 $\mathrm{mE}$ e $9207489.07 \mathrm{mS}), 4$ no Rio Gramame (292756.38 mE e $9201557.22 \mathrm{mS}$ ) e 4 no Riacho do Padre $(298017.81 \mathrm{mE}$ e $92011680.36 \mathrm{mS}$ ). Além de 9 em locais públicos como praças e canteiros centrais (Praça da Independência (293295.51 mE e $9212640.7 \mathrm{mS}$ ), Praça Silvio Porto (296750.58 mE e 9214761 $\mathrm{mS}$ ), Praça do Coqueiral (296262.47 mE e $9206604.32 \mathrm{mS}$ ), Praça da Paz (296372.46 mE e 9209549 mS), Praça Pedro América (291624.94 mE e 9212722.38 mS), Praça Alcides Carneiro (296983.28 mE e 9214567,42 mS), Av. Hilton Solto Maior (294454.76 mE e $9207493.39 \mathrm{mS}$ ) Av. Ministro José Américo de Almeida (293848.29 mE e $9212007.49 \mathrm{mS}$ ) e Rua Bacharel José de Oliveira Curchatuz (296816.35 mE e 9217074.28 mS)).

Para o levantamento arbóreo, além da identificação in loco das espécies nas áreas verdes, foram utilizados como dados secundários o Estudo de Viabilidade Ambiental (EVA) da Área de Implantação do Parque Natural Municipal do Cuiá (JOÃO PESSOA, 2011).

As identificações das espécies arbóreas ocorreram mediante as características taxonômicas (reprodutivas e vegetativas), e posterior comparação com material do Herbário Lauro Pires Xavier da Universidade Federal da Paraíba (UFPB), e literatura especializada por Lorenzi (2008), além de comparações com exemplares depositados e disponibilizados no herbário virtual do Missouri Botanical Garden (TROPICOS, 2019). A nomenclatura foi atualizada pelo site da Lista da Flora do Brasil (REFLORA, 2019), adotando o sistema de classificação do Angiosperm Phylogeny Group IV (APG, 2016).

A identificação in loco da fauna considerou apenas o grupo dos vertebrados, ocorrendo mediante constatações visuais, com auxílio de binoculo e câmera fotográfica, e posterior reconhecimento com especialista e comparação com a bibliografia especializa (PIACENTINI et al., 2015; WILSON; REEDER, 2005; BIOLIB BIOLOGICAL LIBRARY, 2019; DUNNING; RIDGELY, 1989). As visitas foram realizadas nos horários da manhã, entre $09 \mathrm{~h}$ e $11 \mathrm{~h}$, e tarde, entre $13 \mathrm{~h}$ e $17 \mathrm{~h}$, no período de 2015 a 2018, em dias aleatórios. Também foram utilizados vestígios da presença de animais como pegadas, estrumes, ninhos e locais de reprodução.

As espécies da flora e fauna identificadas nas áreas verdes foram tabuladas em uma planilha, sendo organizada em ordem alfabética por família e espécie. Como critério para classificação da existência de relação interespecífica entre a fauna, a flora e as áreas verdes, se utilizou a constatação visual e identificação de vestígios da ocorrência de alguma etapa de vida como desenvolvimento, alimentação, abrigo ou reprodutivo in loco. No que tange a influência das áreas verdes para a conservação da biodiversidade se considerou a existência de ação mútua ou compartilhada entre dois ou mais elementos bióticos e identificação de espécies categorizadas como ameaçadas de extinção (vulnerável, em perigo ou criticamente em perigo), conforme a lista vermelha de espécies brasileiras ameaçadas de extinção (BRASIL, 2014) e da União Internacional para a Conservação da Natureza e dos Recursos Naturais -IUCN (CNCFLORA, 2019). Durante as vistorias in loco foram feitas constatações do usufruto e interações da população com as áreas verdes.

\section{RESULTADOS E DISCUSSÃO}

$\mathrm{O}$ verde urbano existente no município de João Pessoa-PB está localizado nas Unidades de Conservação (UC), parques urbanos, praças, canteiros centrais das avenidas, áreas de preservação permanentes das bacias hidrográficas, falésias vivas e mortas, e áreas definidas no macrozoneamento urbano durante o planejamento urbano como Zonas Especiais de Preservação (ZEP), tratando-se de áreas que apresentam restrições legais em seu uso.

Baseando-se nas observações do usufruto entre a população e estas áreas, existem as áreas verdes de uso direto (onde ocorre o aproveitamento adequado dos recursos naturais existentes, servindo de locais de passagem, descanso ou lazer) tratando-se dos canteiros centrais, jardins, praças públicas e parques, onde os munícipes desfrutam diretamente da área, com árvores distribuídas aleatoriamente, parques infantis e outros atrativos. E as áreas verdes conservadas, constituídas pelos maciços florestal das unidades de conservação, áreas de preservação permanente (APP) e zonas especiais de 
preservação, que apresentam cobertura vegetal nativa e não tem um uso direto e intensivo por parte da população.

Constatou-se que os remanescentes florestais sofrem influência de ações antrópicas, seja mediante a deposição de resíduos sólidos (domésticos, eletrônicos ou construção e demolição), exploração irregular de produtos madeireiros e não madeireiros, e até ocupação irregular. Essas ações foram identificadas tanto em áreas particulares, quanto em áreas protegidas ou de preservação. Se tratando de áreas protegidas, tal degradação foi constatada no: Parque Lauro Pires Xavier; Parque Cabo Branco; Parque Ecológico Augusto dos Anjos; Parque Ecológico Jaguaribe, e; Parque Natural Municipal do Cuiá, além das áreas de preservação nos leitos dos rios e nascentes. Nos Parques Sólon de Lucena e Arruda Câmara, por se tratarem de parques de uso direto pela população e apresentar uma gestão mais efetiva por parte do poder público, fica mais difícil à realização da degradação destes locais.

Esta degradação em remanescentes florestais e áreas preservadas no perímetro urbano acontecem em outras regiões do país. Na Mata do Quilombo, Campinas-SP, no trecho próximo à estrada ocorrem frequentes queimadas, e na mata ciliar, Damame et al. (2019) encontraram descarte de resíduos da construção civil, lixo doméstico, cultos religiosos e tráfego de pessoas. Na região do Centro-Oeste, mas especificamente no município de Porangatu-GO, os impactos ambientais identificados por Costa e Pires (2017) em áreas protegidas foram provocados pelo crescimento populacional e urbano, relacionado ao desenvolvimento local nas últimas décadas. Este mesmo estudo aborda que as principais ações causadoras de impacto são a deposição de resíduos de construção e demolição, resíduos sólidos urbanos, ocupações e desmatamentos, assim como o lançamento de efluentes.

Vale ressaltar que as unidades de conservação (UCs) localizados em áreas urbanas estão sujeitas a diversos agentes degradadores e ações antrópicas com significativos impactos ambientais como desmatamento, caça ilegal, extrativismo predatório, lançamento de águas servidas, deposição de resíduos sólidos (FIGUEIREDO et al., 2017).

Nas áreas urbanas, um agente causador de alteração da paisagem é a população, como relatado nos estudos citados e constatada in loco nos parques municipais. No entanto, no caso do município de João Pessoa, não se pode afirmar se esta degradação ocorre pela falta consciência da população das consequências de suas ações (pela falta de instrução ou educação ambiental) ou pelo desprezo com a natureza, sendo necessário um estudo específico que aborde este tema.

Em estudo realizado nos fragmentos florestais do município de João Pessoa-PB, contatou-se que os mesmos tratam-se de áreas bastante reduzidas, com formas lineares, e com intenso efeito de borda, trazendo uma série de implicações pra fauna e flora (DANTAS et al, 2017). O mesmo estudo alerta para a necessidade de ações para evitar o desaparecimento de espécies, apontando como áreas prioritárias para preservação os remanescentes dos bairros do Muçumagro, Ponta do Seixas, Portal do Sol, Jardim Oceania e Aeroclube, por corresponderem à vegetação ciliar e/ou áreas de nascentes, além de alto grau de fragilidade.

Destaca-se que estes remanescentes indicados por Dantas et al. (2017) como área prioritária para conservação, também é recomendada no Plano de Conservação e Recuperação da Mata Atlântica de João Pessoa (JOÃO PESSOA, 2012), para a mesma finalidade.

No tocante a riqueza de biodiversidade existente no município, o verde urbano que se destaca são as APPs representadas pelas matas ciliares das bacias hidrográficas que cortam o município, remanescentes vegetais, parques urbanos e unidades de conservação. Algumas destas áreas apresentam potenciais a se tornarem parques municipais, devido ao seu estado de conservação faunístico e florístico. No entanto, devido à urbanização, alguns trechos de área de preservação estão sendo modificada, não apresentando mais as suas características naturais.

$\mathrm{Na}$ avaliação geral dos dados coletados referentes às espécies arbóreas e palmeiras que compõem a paisagem das áreas verdes, foram identificadas 92 espécies, de 84 gêneros distribuídos em 38 famílias. Do total de espécies identificadas, 32 foram encontradas tanto em ambiente totalmente urbano, a exemplo das praças, canteiros centrais e parques, quanto em locais naturais, como em vegetação nativa e UC. Em termos de riqueza, a família botânica Fabaceae, se destaca como sendo a mais abundante, com 23 espécies. Este resultado deve-se ao fato da Fabaceae ser considerada a família mais rica e abundante nas florestas da América do Sul (HUECK, 1972).

As espécies vegetais nativas encontradas no paisagismo de praças e jardins públicos, canteiros centrais e trevos das avenidas, deve-se a política pública municipal implantada na última década, de utilização de espécies nativas no paisagismo, com a criação de um viveiro municipal de plantas nativas. A utilização inicial de espécies nativas no paisagismo urbano ocorreu devido ao efeito estético que a vegetação arbórea proporciona ao formato do tronco e da copa, coloração e formato das folhas e da flor, aroma, tipo do fruto, adaptação ao microclima da região e como ferramenta de conservação. No caso das espécies naturalizada ou exótica nos remanescentes florestais, provavelmente é resultante do efeito de borda, onde tais espécies se proliferam após encontrar condições ideais para o seu desenvolvimento nas bordas das matas.

Em estudo realizado por Amazonas e Barbosa (2011), em remanescente da microbacia hidrográfica do Rio Timbó, João Pessoa-PB, os autores identificaram 129 espécies vegetais, de diferentes hábitos, sendo 58 espécies de hábito arbóreo, 27 trepadeira, 24 arbustos, 11 erva, cinco são arbustos escandentes e quatro subarbustos. O quantitativo de espécie encontrada no estudo realizado na microbacia do Rio Timbó mostra que a vegetação existente no município é maior que o identificado neste estudo, no entanto, se for considerado apenas as espécies arbóreas, os valores se aproximam. No presente estudo, foram identificados 73 espécies de hábito arbóreo, enquanto que no estudo realizado na microbacia do Rio Timbó, 58.

O plano municipal de conservação e recuperação de João Pessoa quantificou 550 táxons, distribuídas em 102 famílias de 354 gêneros, de diferentes hábitos (JOÃO PESSOA, 2012). O mesmo plano destaca que ocorre uma predominância de vegetação nativa em estágio inicial e médio de regeneração, no município. Vale ressaltar que este quantitativo preliminar de espécies identificadas se deve a ampla metodologia utilizada, com consultas aos herbários nas universidades da Paraíba e de 
outras regiões, incluindo herbários virtuais fora do país, além de estudos bibliográficos realizados ao longo da última década. Estes valores servem como referência da riqueza da flora existente no município e do potencial que a cidade tem em se tornar um nicho de conservação vegetal, consequentemente da biodiversidade.

No município de Major Sales-RN, Nascimento e Guedes (2015) quantificaram 1.070 indivíduos, de 21 espécies vegetais que compõem a arborização da cidade. Na cidade de TimonMA, Morais e Machado (2014) identificaram 86 espécies vegetais na arborização das ruas, praças e canteiros centrais. No levantamento preliminar, realizado neste estudo, foram identificadas 65 espécies vegetais que compõem a arborização urbana, no entanto, para se obter um valor mais condizente com a realidade, é necessário realizar um inventário da arborização urbana.

Tabela 1. Espécies arbóreas identificadas nas áreas verdes e na arborização urbana do município de João Pessoa, Paraíba, categorizada como ameaçada de extinção.

\begin{tabular}{|c|c|c|c|c|c|}
\hline \multirow{2}{*}{ Família/Espécies } & \multirow{2}{*}{ Nome Comum } & \multirow{2}{*}{ DS } & \multicolumn{2}{|c|}{ In Loco } & \multirow{2}{*}{ Status CNC } \\
\hline & & & $\mathrm{AB}$ & RFN & \\
\hline $\begin{array}{l}\text { BIGNONIACEAE } \\
\text { Handroanthus impetiginosus (Mart. ex DC.) } \\
\text { Mattos }\end{array}$ & Ipê-roxo & $\mathrm{x}$ & $\mathrm{x}$ & $\mathrm{x}$ & NT \\
\hline FABACEAE & & & & & \\
\hline Apuleia leiocarpa (Vogel) J.F.Macbr & Jitaí* & $\mathrm{x}$ & $\mathrm{x}$ & $\mathrm{x}$ & VU \\
\hline Bowdichia virgilioides Kunth & Sucupira-preta & $\mathrm{x}$ & $\mathrm{x}$ & $\mathrm{x}$ & NT \\
\hline $\begin{array}{l}\text { Paubrasilia echinata (Lam.) Gagnon, H.C. } \\
\text { Lima \& G.P.Lewis }\end{array}$ & Pau-brasil* & $\mathrm{x}$ & $\mathrm{x}$ & & $\mathrm{EN}$ \\
\hline LAURACEAE & & & & & \\
\hline Ocotea odorifera (Vell.) Rohwer & Louro-cheiroso* & & & $\mathrm{x}$ & $\mathrm{EN}$ \\
\hline MELIACEAE & & & & & \\
\hline Cedrela fissilis Vell. & Cedro* & & $\mathrm{x}$ & & VU \\
\hline Cedrela odorata L. & Cedro-cheiroso* & & & $\mathrm{x}$ & VU \\
\hline
\end{tabular}

DS: Identificação por dados secundários; In loco: Identificação em campo; AB: Presente na arborização das praças, canteiros e parques; RFN: Presente nos remanescentes florestais naturais; Status CNC: Conservação da espécie; EN: em perigo; NT: quase ameaçada; VU: vulnerável em extinção;*: Consta na lista vermelha das espécies ameaçada de extinção (Portaria MMA nº 443/2014).

Destas, cinco (ipê-roxo (H. impetiginosus), jitaí (A. leicocarpa), sucupira-preta (B. virgiliodes), pau-brasil $(P$. echinata) e cedro (C. fissilis)) foram identificadas fazendo parte da arborização urbana em canteiros centrais, praças e parques, demonstrando que a utilização de espécies nativas na arborização contribui para a conservação ex situ. Duas foram identificadas apenas nos remanescentes florestais (lourocheiroso (O. odorifera) e cedro-cheiroso $(C$. odotara)). O paubrasil ( $P$. echinata) e o cedro ( $C$. fissilis) foram identificados apenas na arborização urbana.

Em estudo realizado na Mata Atlântica Mineira, no Parque Estadual Rio Doce-MG, França e Stehmann (2013) identificaram seis espécies com ameaça de extinção, sendo três na categoria de vulnerável e as demais como em perigo, conforme as listas estadual e nacional de espécies ameaçada. Destaca-se que a espécie louro-cheiroso ( $O$. odorífera) identificada no estudo em Minas Gerais, também foi encontrada em João Pessoa, existindo apenas no remanescente florestal das áreas protegidas.
No presente estudo foram identificadas sete espécies arbóreas classificadas como ameaçada de extinção (Tabela 1). As espécies jitaí (Apuleia leicocarpa), cedro-cheiroso (Cedrela odotara) e cedro (Cedrela fissilis) são classificados como vulneráveis (VU), conforme o Centro Nacional de Conservação (CNCFLORA, 2019) e a Lista vermelha das espécies ameaçada de extinção (BRASIL, 2014). A referida classificação indica que as espécies enfrentam um risco de extinção na natureza. As espécies ipê-roxo (Handroanthus impetiginosus) e sucupirapreta (Bowdichia virgiliodes) estão classificadas como quase ameaçadas (NT), indicando que as mesmas, no momento, não se qualificam como ameaçadas, mas estão perto ou suscetível de serem qualificadas em uma categoria de ameaça num futuro próximo. O pau-brasil (Paubrasilia echinata) e louro-cheiroso (Ocotea odorifera) estão classificadas como em perigo (EN), tratando-se de espécies que enfrentam um risco muito elevado de extinção na natureza. 
encontradas apenas no Parque de Cinquentenário, tratando-se de mata nativa, localizado no perímetro urbano. Vásquez et al.(2016) em estudo realizado da cidade de Iquito, Loreto
(Peru), registraram 56 espécies de aves no ambiente urbano, 84 espécies na área periurbana e 72 nas florestas.

Tabela 2. Fauna identificada in loco nas áreas verdes e na arborização urbana no município de João Pessoa, Paraíba.

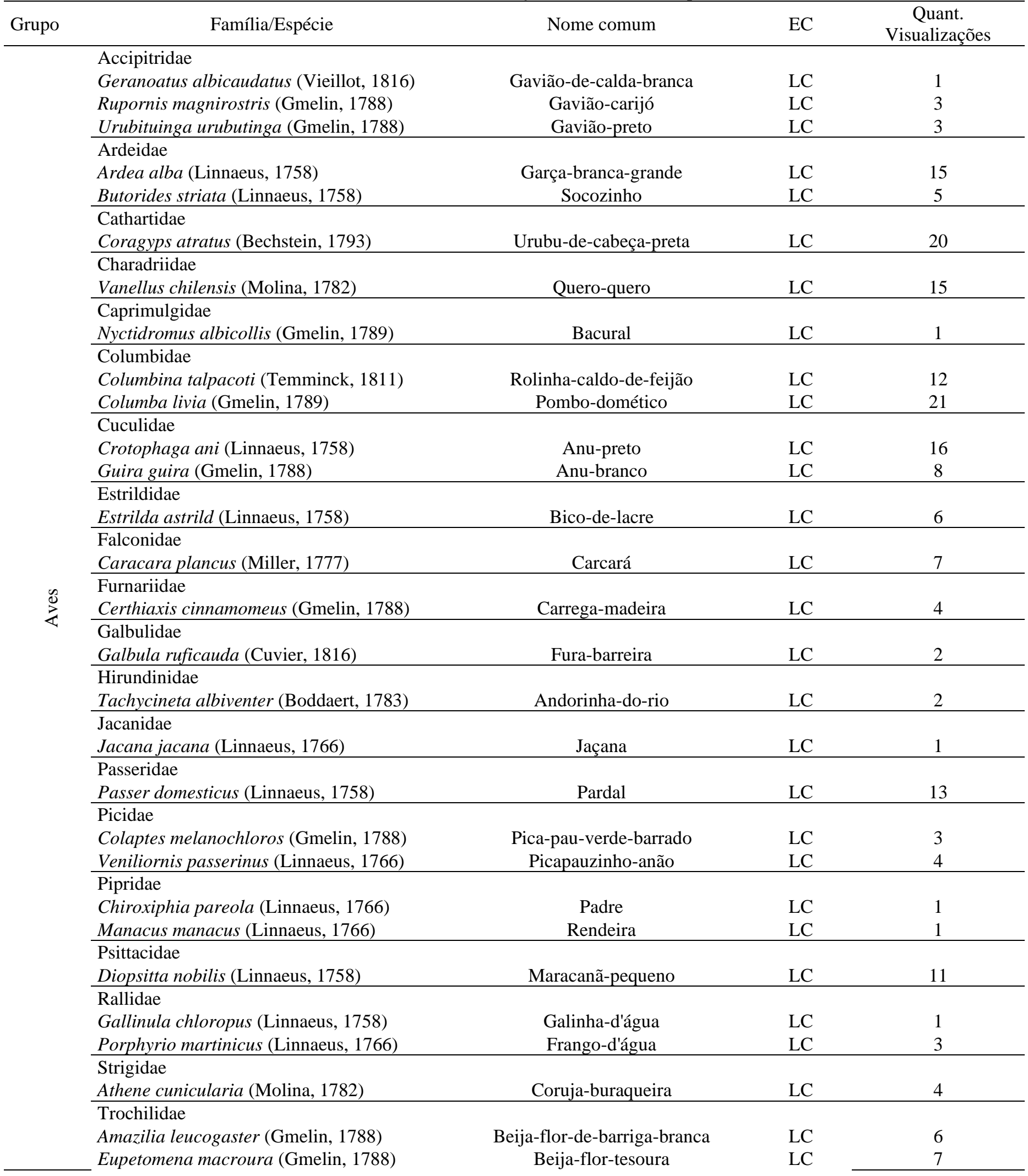




\begin{tabular}{|c|c|c|c|c|}
\hline & $\begin{array}{l}\text { Thraupidae } \\
\text { Coereba flaveola (Linnaeus, 1758) } \\
\text { Thraupis palmarum (Wied, 1823) } \\
\text { Thraupis sayaca (Linnaeus, 1766) }\end{array}$ & $\begin{array}{c}\text { Sibito } \\
\text { Sanhaçu-do-coqueiro } \\
\text { Sanhaçu }\end{array}$ & $\begin{array}{l}\mathrm{LC} \\
\mathrm{LC} \\
\mathrm{LC}\end{array}$ & $\begin{array}{c}12 \\
6 \\
3\end{array}$ \\
\hline & $\begin{array}{l}\text { Troglodytidae } \\
\text { Troglodytes musculus (Naumann, 1823) }\end{array}$ & Rouxinol & & 5 \\
\hline & $\begin{array}{l}\text { Tyrannidae } \\
\text { Fluvicola nengeta (Linnaeus, 1766) } \\
\text { Pitangus sulhuratus (Linnaeus, 1766) } \\
\text { Tyrannus melancholicus (Vieillot, 1819) }\end{array}$ & $\begin{array}{l}\text { Lavadeira } \\
\text { Bem-te-vi } \\
\text { Suiriri }\end{array}$ & $\begin{array}{l}\mathrm{LC} \\
\mathrm{LC} \\
\mathrm{LC}\end{array}$ & $\begin{array}{c}10 \\
15 \\
3\end{array}$ \\
\hline \multirow{8}{*}{ 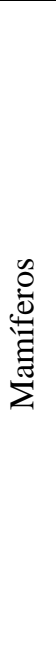 } & $\begin{array}{l}\text { Bradypodidae } \\
\text { Bradypus variegatus (Schinz, 1825) }\end{array}$ & Preguiça & $\mathrm{LC}$ & 3 \\
\hline & $\begin{array}{l}\text { Callitrichidae } \\
\text { Callithrix jacchus (Linnaeus, 1758) }\end{array}$ & Sagui-de-tufos-brancos & $\mathrm{LC}$ & 8 \\
\hline & $\begin{array}{l}\text { Canidae } \\
\text { Cerdocyon thous (Linnaeus, 1766) }\end{array}$ & Cachorro-do-mato & $\mathrm{LC}$ & 1 \\
\hline & $\begin{array}{l}\text { Cavidae } \\
\text { Cavia sp. }\end{array}$ & Preá & & 2 \\
\hline & $\begin{array}{l}\text { Dasyproctidae } \\
\text { Dasyprocta prymnolopha (Wagler, 1831) }\end{array}$ & Cutia & $\mathrm{LC}$ & 1 \\
\hline & $\begin{array}{l}\text { Didelphidae } \\
\text { Didelphis albiventris (Lund 1840) }\end{array}$ & Timbú & $\mathrm{LC}$ & 6 \\
\hline & $\begin{array}{l}\text { Echimyidae } \\
\text { Thrichomys apereoides (Lund, 1839) }\end{array}$ & Capivara & $\mathrm{LC}$ & 1 \\
\hline & $\begin{array}{l}\text { Muridae } \\
\text { Rattus novergicus (Berkenhout, 1769) }\end{array}$ & Gabiru & $\mathrm{LC}$ & 5 \\
\hline \multirow{9}{*}{$\frac{0}{2}$} & $\begin{array}{l}\text { Alligatoridae } \\
\text { Caiman latirostris (Daudin, 1802) }\end{array}$ & Jacaré-de-papo-amarelo & $\mathrm{LC}$ & 2 \\
\hline & $\begin{array}{l}\text { Amphisbaenidae } \\
\text { Amphisbaena alba (Linnaeus 1758) }\end{array}$ & Cobra-de-duas-cabeças & $\mathrm{LC}$ & 1 \\
\hline & $\begin{array}{l}\text { Boidae } \\
\text { Boa constrictor (Linnaeus, 1758) }\end{array}$ & Jibóia & $\mathrm{LC}$ & 1 \\
\hline & $\begin{array}{l}\text { Chelidae } \\
\text { Phrynops geoffroanus (Schweigger, 1812) }\end{array}$ & Cágado & $\mathrm{LC}$ & 3 \\
\hline & $\begin{array}{l}\text { Colubridae } \\
\text { Philodryas nattereri (Steindachner 1870) }\end{array}$ & Cobra-corre-campo & $\mathrm{LC}$ & 2 \\
\hline & $\begin{array}{l}\text { Iguanidae } \\
\text { Iguana iguana (Linnaeus, 1758) }\end{array}$ & Iguana & $\mathrm{LC}$ & 3 \\
\hline & $\begin{array}{l}\text { Philodryas } \\
\text { Philodryas sp. }\end{array}$ & Cobra-cipó & & 2 \\
\hline & $\begin{array}{l}\text { Teiidae } \\
\text { Tupinambis teguixin Linnaeus, } 1758\end{array}$ & Teiju & $\mathrm{LC}$ & 6 \\
\hline & $\begin{array}{l}\text { Tropiduridae } \\
\text { Tropidurus torquatus (Wied, 1820) }\end{array}$ & Lagartixa & $\mathrm{LC}$ & 12 \\
\hline
\end{tabular}

EC: Estado de conservação da espécie; LC: Menos preocupante; Quant. Visualizações: quantidade de visualizações dos respectivos animais em campo.

Em relação à avefauna de João Pessoa, o quantitativo de espécie encontrada no presente estudo foram maiores que os identificados no município de Maringá e inferior ao encontrado no plano da Mata Atlântica e no município de Iquito. A abundância do grupo de aves encontrada neste estudo decorre da facilidade de locomoção que os mesmos têm em comparação aos demais grupos de fauna. A urbanização, fragmentação e a dinâmica da cidade, dificulta a locomoção dos demais grupos, pois precisam percorrer grandes distâncias no solo, sendo vulneráveis a predadores e ações humanas.
Em cinco fragmentos florestais no município de JoinvilleSC, Dorrnelles et al. (2017) registraram 32 espécies de mamíferos de 13 famílias, sendo o maior quantitativo do grupo dos pequenos mamíferos, representados principalmente por quirópteros, registrando também grupos de carnívoros. A diferença no quantitativo encontrada neste estudo e no município de Joinville/SC é em decorrência do método utilizado para identificação das espécies, o primeiro utilizou-se apenas de observação direta (visual) e vestígios, e o segundo de captura, observação direta e armadilhas. 
Em um fragmento florestal no perímetro urbano de Patos de Minas-MG, Lima e Gonçalves (2016) identificaram 10 espécies de mamíferos, distribuídas em seis ordens, sendo apenas uma identificada com status de conservação considerada ameaçada. Este mesmo estudo concluiu que o remanescente em questão desempenha um papel importante para a conservação da mastofauna da região, tendo como função área de refúgio.

Na Reserva Biológica Tamboré, Santana de Paranaíba-SP, tratando-se de um remanescente do perímetro urbano de São Paulo, Fuentes et al. (2017) identificaram 14 espécies de répteis, sendo seis de lagarto e oito de serpente, onde nenhuma consta na lista de espécies ameaçadas de extinção. Número maior que o identificado neste estudo, e menor que o catalogado pelo Plano de Conservação da Mata Atlântica (JOÃO PESSOA, 2012).

Em uma formação vegetal de restinga no Estado da Paraíba, Campos et al. (2018) encontraram 30 espécies de mamíferos, distribuídas em 16 famílias. Quantidade menor que o encontrado por Feijó et al. (2016), na Reserva Biológica Guaribas, Paraíba, onde identificaram 70 espécies, distribuídas em 23 famílias.

Com relação à interação identificada entre a fauna e a flora no perímetro urbano de João Pessoa, foi observada uma harmonia direta entre o Pica-pau-verde-barrado (Colaptes melanochloros) e o Picapauzinho-anão (Veniliornis passerinus) e os indivíduos vegetais da família da Arecaceae, em especial o coqueiro (Cocos nucifera) e palmeira-mexicana (Veitchia merrillii). Constatou-se que alguns indivíduos das espécies vegetais, presentes na arborização e parques, estavam sendo utilizados como locais de nidificação e abrigo, sendo registradas algumas entradas e saídas das respectivas aves dos ninhos.

$\mathrm{Na}$ área de preservação do riacho do Padre, zona sul do município foram constatadas a presenta de um adulto e um jovem da avefauna conhecida como padre (Chiroxiphia pareola), um lagarto iguana (Iguana iguana) jovem, as margens da nascente, e a ave fura-barreira (Galbula ruficauda). A presença de indivíduos jovens nesta área indica que a fauna existente no local em questão, encontra condições adequada ou suficiente para manter um ciclo reprodutivo. No entanto, estudo relata que a falta de contato entre grupos faunísticos, poderá acarretar uma erosão genética, com o cruzamento entre os indivíduos de um mesmo grupo genético ou similar geneticamente, tornando a população mais vulnerável a extinção (SANTOS; SILVA, 2015).

$\mathrm{Na}$ mata ciliar do rio Torres, cidade de San José-Costa Rica, as aves desempenham um importante papel de dispersão de sementes na área urbana, onde os remanescentes florestais urbanos tornam-se uma importante fonte de alimento e abrigo para as comunidades de aves urbanas, em troca, favorecem a regeneração de áreas verdes, melhorando a entrada de sementes e facilitando as etapas de sucessão ecológica nas áreas degradadas (QUESADA-ACUÑA et al., 2018).

Em João Pessoa, foram constados em indivíduos arbóreos e arbustivos, de jardins públicos, parques e praças, a presença de ninhos de aves, sendo as mais visíveis às espécies rolinhade-calda-de-feijão (Columbina talpacoti), rouxinol (Troglodytes musculus), beija-flor-tesoura (Eupetomena macroura), bem-tevi (Pitangus sulhuratus) e sibito (Coereba flaveola). A espécie quero-quero (Vanellus chilensis) é facilmente encontrada em campos abertos, principalmente em jardins gramados, campos de futebol e área de lazer gramada. A coruja-buraqueira (Athene cunicularia) pode ser vista em área com vegetação de porte herbáceo/arbustivo, locais com pouca movimentação de pessoas ou as margens de UC.

A utilização da vegetação existente em locais públicos ou privados para alimento e nidificação, por parte das aves, não ocorre apenas em João Pessoa. No município de Iquito, LoretoPerú, os pomares frutíferos existentes na grande maioria das residências servem de lugar para descanso, alimentação e nidificação para a avefauna (VÁSQUEZ et al., 2016).

Outro vestígio identificado foi à presença de frutos predados por animais, sendo os mais comuns pela a avefauna, se destacando as espécies vegetais: cajueiro (Anacardium occidentale L.); mangueira (Mangifera indica L.), aroeira-dapraia (Schinus terebinthifolia Raddi); cajazeira (Spondias mombin L.); araticum (Annona sp.); mangabeira (Hancornia speciosa Gomes); piriquiteira (Trema micranta (L.) Blume); castanhola (Terminalia catappa L.); ingá (Inga blanchetiana Benth e Inga capitata Desv.); fícus (Ficus bejamina L.); goiaba (Psidium guajava L.); araçá (Psidium guianeenses Sw.); jambeiro (Syzygium malaccenses (I.) Merr. \& I.M.Perry); oliveira (Syzygium cumini (L.) Skeels); jenipapo (Genipa americana L.); angélica (Guettarda platypoda DC.), e; pitombeira (Talisia esculenta (Cambess.) Radlk). Esta constatação confirma a interação existente no município entre os grupos da fauna e flora.

Com relação aos mamíferos, a grande maioria das espécies identificadas, cinco, podem ser encontradas apenas nos remanescentes florestais. O sagui (Callithrix jacchus) e o timbu (Didelphis albiventris) podem ser encontrados também circulando nas praças, parques e locais bem arborizados, sendo espécies muito adaptada ao perímetro urbano do município. O gabiru (Rattus novergicus) geralmente é encontrado em locais com disponibilidade de alimentos, depósitos de lixos clandestinos as margens de remanescentes florestais e residências. Poucas foram às espécies de mamíferos silvestres encontrados circulando fora dos remanescentes florestais, devendo ser uma questão de hábito ou adaptabilidade. Isto indica a necessidade de se criar áreas protegidas como UC para preservar este grupo de animais, além de corredores ecológicos para evitar o isolamento de populações.

O grupo dos répteis segue o mesmo hábito da maioria dos mamíferos, exceto a lagartixa (Tropidurus torquatus), os demais têm hábitos florestais, sendo encontrados em áreas de preservação, parques com vegetação nativa e UC. A lagartixa (T. torquatus) corresponde a uma espécie bem adaptada, sendo encontradas nas árvores que compõe a arborização urbana, parques, praças, borda das matas e residências.

$\mathrm{Na}$ comparação dos resultados encontrados neste trabalho com os demais estudos apresentados, de outras localidades, percebe-se que o município de João Pessoa apresenta uma diversidade de espécies relevantes, se destacando a avefauna e a flora ameaçada de extinção presente na arborização. Mesmo assim, há a necessidade de se criar, sustentar, implantar e fiscalizar áreas protegidas para manter esta diversidade conservada, pois existem espécies de fauna e flora identificadas, unicamente, em locais com bom estado de conservação. 


\section{CONCLUSÕES}

O verde urbano existente no município de João Pessoa, Paraíba contribui para a conservação da flora nativa do bioma Mata Atlântica e de espécies vegetais ameaçadas de extinção, mediante a existência de áreas protegidas e da utilização das mesmas na arborização urbana das praças, parques, jardins e canteiros centrais. Sendo identificadas sete espécies da flora categorizada como ameaçada de extinção.

Há existência de grupos de aves, mamíferos e répteis, utilizando as áreas verdes, remanescentes florestais e a vegetação da arborização para alimento, abrigo ou locais de reprodução.

Algumas espécies da flora e fauna são encontradas, unicamente, nos remanescentes florestais, indicando a necessidade de criação de áreas protegidas e com conectividade, para manter um fluxo gênico entre as populações.

\section{REFERÊNCIAS}

AMAZONAS, N. T.; BARBOSA, M. R. V. Levantamento florístico das angiospermas em um remanescente de Floresta Atlântica Estacional na Microbacia Hidrográfica do Rio Timbó, João Pessoa, Paraíba. Rev. Nordestina de Biologia, v. 20, n, 2, p. 67-78, 2011.

ANGIOSPERM PHYLOGENY GROUP (A.P.G) IV. 2016. An update of the Angiosperm Phylogeny Group classification for the orders and families of flowering plants: APG IV. Botanical Journal of the Linnean Society, London, v. 181, p. 1-20, 2016. 10.1111/boj.12385.

ARROYAVE-MAYA, M.; POSADA-POSADA, M.; NOWAK, D.; HOEHN, R. Remoción de contaminantes atmosféricos por el bosque urbano em el valle de Aburrá. Colombia Forestal, v. 22, n.1, p. 5-16, 2018. 10.14483/2256201X.13695

BIOLIB BIOLOGICAL LIBRARY. Taxon Profile. República Checa. 2019. Disponível em: <https://www.biolib.cz/en/taxon/id14923/>. Acesso em: $20 \mathrm{de}$ fev. 2019.

BOGIANI, P. A.; ARANDA, R.; MACHADO, C. O. F. Riqueza de borboletas (lepidóptera) em um Fragmento Urbano de Cerrado em Mato Grosso do Sul, Brasil. EntomoBrasilis, v. 5, n. 2, p. 93-98, 2012.

BRASIL. Ministério do Meio Ambiente. Portaria $\mathrm{n}^{\circ}$ 443, de 17 de dezembro de 2014. Lista Nacional Oficial de Espécies da Flora Ameaça de Extinção. Brasília-DF, 2014.

CAMPOS, B. A. T. P.; FEIJÓ, A. BRENNAND, P. G. de G.; PERCEQUILLO, A. R. Mammals of a restinga forest in Mataraca, Paraíba, northeastern Brazil, and its affinities to restinga áreas in Brazil. Biota Neotropica, v. 18, n. 1, 2018. 10.1590/1676-0611-bn-2017-0392.

CNCFLORA. Centro Nacional de Conservação da Flora. Lista Vermelha. Instituto de Pesquisas Jardim Botânico do Rio de
Janeiro, Rio de Janeiro/RJ. 2019. Disponível em: $\langle$ http://cncflora.jbrj.gov.br/portal/pt-br/listavermelha $>$.

Acesso em: 20 de fev. 2019.

CREPALDI, M. T.; FERREIRA, M. E. C. Comparativo da avifauna do Parque do Cinquentenário com a área urbana de Maringa-PR. Caderno Prudentio de Geografia, n. 40, v. 1, p. 134-146, 2018.

COSTA, M. I. F.; PIRES, M. G. Levantamento dos impactos ambientais em áreas de preservação permanentes (APPS) urbanas em Porangatu-GO. Revista Meio Ambiente e Sustentabilidade, v. 13, n. 6, p. 135 - 157, 2017. $\underline{10.22292 / \mathrm{mas} . v 13 \mathrm{i} 6.690}$.

DAMAME, D. B.; OLIVEIRA, E. D.; LONGO, R. M. Impactos ambientais pelo uso e ocupação do solo em sub bacias hidrográficas de Campinas, São Paulo, Brasil. Acta Brasiliensis, v. 3 , n.1, p. 1-7, 2019. $10.22571 / 2526-4338108$

DANTAS, M. S.; ALMEIDA, N. V.; MEDEIROS, I. A.; SILVA, M. D. Diagnóstico da vegetação remanescente de Mata Atlântica e ecossistemas associados em espaço urbano. Journal of Environmental Analysis and Progress, v. 02, n. 01, p. 87-97, 2017. 10.24221/jeap.2.1.2017.1128.87-97

DORNELlES, S. S.; EVARISTO, G. H.; TOSETTO, M.; MASSANEIRO, C.; SEIFERT, V. R.; RABOCHA, B.; GONÇALVES, J.; VALENTIM, C. Diversidade de mamíferos em fragmentos florestais urbanos na Bacia Hidrográfica do Rio Cachoeira, Joinville, SC. Acta Biologia Catarinense, v. 4, n. 3, p. 126-135, 2017. 10.21726/abc.v4i3.458

DUNNING, J. S.; RIDGELY, R. South American Birds: A Photographic Aid to Identification. Harrowood Book, $1^{\mathrm{a}}$ trade pbk edition, 1989.

ESTRADA, M. A.; CORIOLANO, R. E.; SANTOS, N. T.; CAIXEIRO, L. R.; VARGAS, A. B.; ALMEIDA, F. S. Influência de áreas verdes urbanas sobre a Mirmecofauna. Floresta e Ambiente, v. 21, n.2, p. 162-169, 2014. $\underline{10.4322 / \text { floram.2014.035. }}$.

FEIJÓ, A.; NUNES, H.; LANGGUTH, A. Mamíferos da reserva biológica Guaribas, Paraíba, Brasil. Revista Nordestina de Biologia, n. 24, v. 1, p. 57-74, 2016.

FIGUEIREDO, H. P.; CONSTANTINO, M.; BARROS, J. H. S.; COSTA, R. B. Políticas públicas e fragilidade na gestão de Unidades de Conservação Urbanas no Brasil. Multitemas, v. 22, p. 217-234, 2017. 10.20435/multi.v22i51.1316.

FRAÇA, G. S.; STEHAMANN, J. R. Florística e estrutura do componente arbóreo de remanescentes de Mata Atlântica do Médio rio Doce, Minas Gerais, Brasil. Rodriguésia, v. 64, n.3, p. $607-624,2013$. 10.1590/S2175-78602013000300012.

FUENTES, R. A. G.; KATO, K.; GHELLERE, J. M. B.; DIXO, M. Numa selva de pedra uma ilha de Mata Atlântica: a 
herpetofauna da Reserva Biológica Tamboré, Santana de Parnaíba, SP. Oecologia Austraçis, n. 21, n.3, p. 292-301, 2017. 10.4257/oeco.2017.2103.06.

HUECK, K. As florestas da América do Sul: Ecologia, composição e importância econômica. São Paulo: Universidade de Brasília; Polígono, 465p, 1972.

INSTITUTO BRASILEIRO DE GEOGRAFIA E ESTATÍSTICA. Cidades: João Pessoa. Rio de Janeiro. 2019. Disponível em: <https://cidades.ibge.gov.br/brasil/pb/joaopessoa/historico $>$. Acesso em: 20 de mar. 2019.

JOÃO PESSOA. Secretaria Municipal de Meio Ambiente. Plano Municipal de Conservação e Recuperação da Mata Atlântica de João Pessoa. João Pessoa: FEA Gráfica e Editora. 2012.

JOÃO PESSOA. Secretaria Municipal de Meio Ambiente. Estudo de Viabilidade Ambiental (EVA) da Área de Implantação do Parque Natural Municipal do Cuiá, João Pessoa-PB. João Pessoa: SEMAM. 2011.

LIMA, F. J. C.; GONÇALVES, R. C.; Levantamento de mastofauna na Mata do Catingueiro em Patos de Minas. Revista Cerrado Agrociências, v.7, p. 38-48, 2016.

LONDE, P.R.; MENDES, P. C. A influência das áreas verdes na qualidade de vida urbana. Hygeia, v. 10, n. 18, p. 264-272, 2014.

LORENZI, H. Árvores Brasileiras: Manual de identificação e cultivo de plantas arbóreas nativas do Brasil. Vols 1, 2 e 3. $5^{\text {a }}$ Ed. Instituto Plantarum Ltda. Nova Odessa, São Paulo. 2008.

MACIEL, T. T.; BARBOSA, B. C. Áreas verdes urbanas: história, conceito e importância ecológica. CES Revista, v. 29, n. 1, p. 30-42, 2015.

MELO, Í, V.; MOURA, G. J. B.; FREITAS, M. A.; ANDRADE, E. V. E.; CASAL, C.; ABEGG, A. D.; KOKUBUM, M. N. C. New additions to the herptofauna of the Dois Irmão State Park, an urban Atlantic Rainforest fragment in northeastern Brazil. Herptology Notes, v. 11, p. 245-254, 2018.

MORAIS, L. M. F. A. Expansão urbana e qualidade ambiental no litoral de João Pessoa-PB. Dissertação (Mestrado em Geografia). Universidade Federal da Paraíba, UFPB, Brasil. 2009.

MORAIS, L. A.; MACHADO, R. R. B. A Arborização urbana do município de Timon/MA: Inventário, diversidade e diagnóstico quali-quantitativo. REVSBAU, v. 9, n. 4, p. 80-98, 2014. 10.5380/revsbau.v9i4.63298.

NASCIMENTO, J. F.; GUEDES, J. A Arborização urbana do espaço público de Major Sales. Caderno de Estudos Geoambientais-CADEGEO, v. 06, n. 01, p. 17-31, 2015.
PIACENTINI, V. de Q.; ALEIXO, A.; AGNE, C. E.; MAURÍCIO, G. N.; et al. Annotated checklist of the birds of Brazil by the Brasilian Ornithological Records Committee. Revista Brasileira de Ornitologia, v. 23, n. 2, p. 91-298, 2015.

PINHEIRO, R. T.; MARCELINO, D. G.; MOURA, D. R.; Espécies arbóreas de uso múltiplo e sua importância na conservação da biodiversidade nas áreas verdes urbanas do município de Palmas, Tocantins. Desenvolvimento e Meio Ambiente, v. 49, p 264-282, 2018. 10.5380/dma.v49i0.59315.

QUESADA-ACUÑA, S. G.; MARTINEZ, C. P.; ALÁN, O. R.; GASTEZZI-ARIAS, P. Dispersión de semillas por aves residentes em bosque ribereño urbanos del río Torres, San José, Costa Rica. UNED Research Journal, v. 10, n.1, p. 48-56, 2018. $\underline{10.22458 / \text { urj.v10i1.2040. }}$.

REFLORA. Instituto de Pesquisa Jardim Botânico do Rio de Janeiro. Herbário Virtual. Rio de Janeiro. 2019. Disponível em:<http://reflora.jbrj.gov.br/reflora/herbarioVirtual/ConsultaP ublicoHVUC/ConsultaPublicoHVUC.do>. Acesso em: 24 jan. de 2019.

SANTOS, I. M.; CALADO, D. Captura de mosquito antropofílicos (Diptera, Culicidae) em uma área urbana da região oeste da Bahia, Brasil. Iheringia, Série Zoologia, v.104 n.1, p. 32-38, 2014. 10.1590/1678-4766201410413238.

SANTOS, C. R. dos; SILVA, R. V. da. Passagem inferior de fauna e cerca guia como forma de mitigação dos impactos ambientais. Revista Internacional de Ciências, v. 5, n. 2, 2015. $\underline{10.12957 / \text { ric.2015.19647 }}$

SEVERINO, A. J. Metodologia do trabalho científico. São Paulo: Cortez, 23 ${ }^{\mathrm{a}}$ ed. 2007.

TROPICOS. Missouri Botanical Garden. 2019. Disponível em: <https://www.tropicos.org/>. Acesso em: 01 mar. 2019.

VÁSQUEZ, M. del P. O.; ZUMAETA, L. M. Q.; DÍAZ, R.. P.; DÍAZ, A. A. Diversidad de aves em ambientes urbanos y periurbanos de la ciudade de Iquitos y bosques de varillal, Loreto, Perú. Conoc. Amaz, v. 7, n. 1, p. 3-13, 2016.

VILANOVA, S. R. F.; MAITELLI, G. T. A importância da conservação de áreas verdes remanescentes no centro político administrativo de Cuiabá-MT. UNICiências, v. 13, p. 87-103, 2009.

WILSON, D. E.; REEDER, D. M. (Eds). Mammal Species of the World: A Taxonomic and Geographic Reference. $3^{\circ}$ ed. Baltimore,Maryland: Johns Hopking University Press, , 2005. 2.142 p.. Disponível em: <https://www.departments.bucknell.edu/biology/resources/msw 3/>. Acesso em: 20 de fev. 2019. 